\title{
Observation of education team towards objective structured clinical examination (OSCE) in the faculty of medicine, national Ribat University, Sudan
}

\begin{abstract}
Objective Structured Clinical Examination is an evaluation method that based on goal testing and direct observation of student performance during planned clinical examination The OSCE was intended to overcome the shortage in the traditional methods of assessments. It focuses on the standardization of scoring, structure and blueprinting of the exam; this descriptive cross-sectional study, that aims to evaluates OSCE as a clinical examination tool from teaching staff point of view faculty of medicine, National Ribat University. The sample of the study integrated all teaching staff from the clinical departments (pediatrics, obstetrics, surgery and medicine) throughout the period 2014-2016 The total number of academic staff in these departments was 61; all of them were included in the study. A specially designed questionnaire was used to collect data from the staff. The Statistical Package for Social Sciences (SPSS) was used for data analysis. The results of the study were presented. The majority of Academic staff (Ninety two percent) preferred OSCE as a tool of assessment, OSCE is helpful as an assessment tool as $(76.7 \%)$ of them answered and its relevant to the educational value as $(68.9 \%)$ and it meets the objectives of the courses according to the opinion of $(73.8 \%)$ of them. with good coverage to the different tasks and content of the course by $(76.7 \%)$ of them. In addition, $86.9 \%$ of them commented on students' performance in OSCE that it was good and $78.7 \%$ of them evaluated students' achievement in OSCE compared to conventional as good. OSCE is repetitive for the examiner and they felt restricted in OSCE as examiners as $(62 \%)$ of them answered. We conclude that OSCE was seen as a positive and a useful practical experience by most of the teaching staff faculty of medicine National Ribat University. And we recommend more training for teaching staff in OSCE implementation.
\end{abstract}

Keywords: OSCE, Sudanese, medical students, teaching staff, Sudan
Volume 3 Issue 4 - 2019

\author{
Sulafa G Salim,' 'Mohammed M Eltayeb, ${ }^{2}$ Mosab \\ N Mohammed, ${ }^{2}$ Yousif M ELhaj' \\ 'Education Development and Research Center, Faculty of Medicine, \\ Gezira University, Sudan \\ ${ }^{2}$ Medical Parasitology department, FMLS, Alneelain University, \\ Sudan
}

Correspondence: Mosab N Mohammed, Medical Parasitology department, FMLS, Alneelain University, Sudan, Tel 2499|2659582, Email musab.noorI3@gmail.com

Received: May 31, 2019 | Published: July 23, 2019

\section{Introduction}

The medical education field is quickly growing, and with current advances in the assessment and evaluation of medical students, the majority of medical schools utilize the objective structured clinical examination (OSCE) in evaluating medical student's performance. The account by Harden et al. ${ }^{4}$ was the first to describe the OSCE structure and organization. Consequently, many medical schools embraced this method, and it represents a major tool of assessment and evaluation. OSCE is a method that can be used to evaluate different learning domains. These comprise cognitive, psychomotor and affective domains. ${ }^{1}$ Miller et al. ${ }^{2}$ developed a clinical evaluation framework that could be applied in evaluating medical students in four main areas (knowledge, competence, performance, and action). The bottom of this pyramid is built by knowledge and is frequently assessed by objective testing. On the other hand, the students must be acquainted with how to use and analyze this knowledge, which constitute the second level of Miller's pyramid (know how). Capability based assessment is one of the methods introduced to objectively evaluate the "knows how" category in this framework. The subsequently level in Miller's pyramid is to evaluate performance (shows how). The OSCE falls within this level, where it is a practical tool to explore the ability of the candidate to "show how" to perform certain skills in a simulated environment. The top element of the pyramid contains an assessment of what physicians do in their practice. ${ }^{2}$
The OSCE evaluates the competence of students in a structured and systematic arrangement that reduce subjectivity. ${ }^{3}$ In 1975, Harden $^{4}$ and his colleagues initiated the objective structured clinical examination (OSCE), maintaining that it fulfilled all the criterion of a perfect method of evaluation of clinical competence. Newble $\mathrm{DI}^{5}$ Four criterion, comprising validity, reliability, objectivity, and practicability or feasibility, must be measured in developing any method of assessment. OSCE is an evaluation method in which the components of clinical competence such as focus history taking, physical examination, simple procedures, and explanation of lab results, patient management problems, communication, and attitude are tested using agreed check lists and rotating the student round a number of stations some which have observers with cheek lists. ${ }^{6}$ The OSCE assessment consists of about 10 stations each of which requires about 8-10minutes of time. All stations should be able of being completed in the same time. The students are moved through all stations and have to move to the next station at the signal. Since the stations are usually self-governing students can begin at any of the procedure stations and complete the cycle. Thus, using 10 stations of 8 minutes each; 10students can finish the examination within 80 minutes. Each station is intended to test a component of clinical competence. At some stations named the procedure stations spectators with agreed check lists to score the student's performance. At other stations named "response stations", students react to questions of the objective type or interpret data or record their findings of the preceding procedure station. ${ }^{6}$ 


\section{Power of OSCE}

It has the benefit that it allows a large number of competencies to be evaluated in manners which are the identical for all candidates. The OSCE permits examiners to decide in advance those competencies to be tested and subsequently to design the examination to test these competencies. The examination covers a wide range of clinical skills under varying degrees of difficulty and complexity much wider than a conventional examination. The scoring is purpose, since standards of competence are fixed and agreed check lists are used for scoring. Where questions are inquired in response stations, these are always objective. Simulation can be used for acute conditions and there is scope for instant feedback. Patient unpredictability and examiner variability are eliminated thus increasing the validity of the examination. ${ }^{3}$

\section{Limitation of OSCE}

The noticeable troubles relate to time and money. In several cases the work and planning in setting up an OSCE is not only time consuming but also costly. The cost-efficiency of the exercise must be taken into consideration. The constraints of time may lessen the qualities of listening and understanding, important for a skilled general practitioner. ${ }^{7}$ Worrying to students and examiners, and auditor feel his function is a minor one specially when using checklist. ${ }^{8}$

\section{Rationale}

The Objective Structured Clinical Examination (OSCE) in some institutions became the popular instrument used to evaluate clinical skills, attitudes and behaviors that are considered standards used by practitioners in the care of their patients. Whereas the core components are the same, the philosophy and implementation by different institutions with varying resources are different.

\section{Objectives}

General objective: To evaluate OSCE as a clinical examination tool from teaching staff point of view.

\section{Specific objectives:}

I. To determine teaching staff opinion on OSCE

II. To assess the processes adopted in constructing the OSCE

III. To determine teaching staff opinion on student's performance in OSCE

IV. To identify teaching staff perception on student's achievement in OSCE compared to traditional clinical examination

V. To assess the training of teaching staff in OSCE.

\section{Materials and methods}

\section{Study setting}

National Ribat university faculty of medicine, Khartoum, Sudan. Is a national university in Khartoum and the School of Medicine were founded in 1999.The faculty mission is to serves the public good through excellence in medical and health professions' education, research and patient care. And to build partnerships that is essential to a high-performing academic health sciences centre. The current staff of faculty and par timers from other universities is 61 .

\section{Study design}

This study is descriptive cross-sectional study design.

\section{Study population}

Population of the study Consist of academic staff full time and parttimers in National Ribat University, faculty of Medicine, Khartoum, Sudan.

\section{Study sample}

The sample included teaching staff from the clinical departments (pediatrics, obstetrics, surgery and medicine). The total number of academic staff in these departments was 61 ; they were included all in the study.

\section{Study instruments}

A predesigned well prepared, self administered questionnaire was used for data collection from teaching staff Faculty of Medicine National Ribat University in the following area:

I. Personal data

II. Received training in student's assessment?

III. Preference of OSCE as assessment tool, and relevance to the educational benefits

IV. Coverage of OSCE to the different task \& content included involving focus history taking \&physical examination

V. OSCE as a tool for assessing knowledge-interpretation\& problem solving?

VI. Students' performance and achievement in OSCE.

\section{Statistical analysis}

Data was entered and analyzed using (SPSS).

\section{Ethical approval}

The study was presented to the ethics review of Education Development and Research Center (EDC), Faculty of Medicine, University of Gezira. Permission to conduct the study was requested from the Faculty of Medicine, National Ribat University administrators, explaining the purpose and the objectives of the study to the faculty administrators and the teaching staff.

\section{Results}

Generally, the Academic staff faculty of medicine national Ribat University feedback about OSCE was positive. It was clear that $92 \%$ of them preferred OSCE as a tool of assessment. Fifty two percent of the staff of faculty of medicine National Ribat University was assistant professors, associate professors were $21.3 \%$, lecturer is $21 \%$ and professors are $4 \%$. Fifty percent of the staff of faculty of medicine Ribat University there Years of experience in university teaching range from $10-15$ years, $32 \%$ from $5-10$ years and $16 \%$ have experience more than 15 years. Sixty tow percent of academic staff faculty of Medicine faculty of medicine Ribat University received courses in students assessment and only $19 \%$ of them had certification in students assessment. Ninety eight percent of the of staff faculty of medicine National Ribat University provided positive feedback 
about the quality of OSCE performance in terms of the clarity of the instructions of the exam, and about the adequacy of station time $70 \%$ of the academic staff commented as average while $(28.3 \%)$ of them rated as short. The Accuracy in Standardized Patient of cases is critical for candidates attempting to demonstrate proficiency in clinical skills during the OSCE, $82 \%$ of staff faculty of medicine National Ribat University rated the reality of clinical stations as good and $72.1 \%$ rated the level of simulated patients' reality as good.

Reasons of OSCE popularity among medical .educators compared to conventional that OSCE covers many areas due to large number of stations, and that it reflects the tasks taught. And the opinion of (68.9\%) of them that it's relevant to the educational value and its useful as an assessment tool as $(76.7 \%)$ of them answered. The OSCE meet the objectives of courses was the opinion of (73.8\%) of them, and $75.4 \%$ of them rated educational value of OSCE as good, Ninety five percent of the staff used to evaluate their questions. Seventy eight percent of staff opinion in student's performance in OSCE exam was good. Among staff of the Faculty of medicine National Ribat University $75.4 \%$ rated the coverage of OSCE to the different task and content included involving focus history taking and physical examination by good, (76.7\%) of them rated OSCE as an acceptable method for assessing practical clinical skills of medical students by good and $60 \%$ of them rated the OSCE as good tool for assessing knowledge. Staff of faculty of medicine National Ribat University asked about if OSCE is monotonous for them (62\%) of them answered yes and that they are restricted in OSCE as examiner. OSCE was seen as a positive and a useful practical experience by most of staff faculty of medicine National Ribat University. ${ }^{9}$

\section{Conclusion and recommendations}

We conclude that OSCE was seen as a positive and a helpful sensible practice by most of the teaching staff faculty of medicine National Ribat University. And we recommend more training for teaching staff in OSCE performance.

\section{Funding details}

None.

\section{Acknowledgments}

We are very grateful to medical students and teaching staff at the faculty of medicine, National Ribat University, Sudan for their support and share in our project.

\section{Conflicts of interest}

The author declares there is no conflict of interest.

\section{References}

1. Bloom BS, Krathwohl DR, Masia BB. Taxonomy of educational objectives: The classification of educational goals handbook: Cognitive domain [s.1.]. New York. 1974. p.1-216.

2. Miller GE. The assessment of clinical skills/competence/performance. Acad Med. 1990;65(9 Supple):S63-S67.

3. Harden RM. What is an OSCE? Medical Education. 2011;45:1181-1189.

4. Harden RM, Stevenson M, Downie WW. Assessment of clinical competence using objective structured clinical examinations. $\mathrm{Br}$ Med $\mathrm{J}$. 1975;1(5955):447-451.

5. Newble DI, Baxter A, Elmslie RG. A comparison of multiple- choice test and free -response test in examination of clinical competence. Med Edu updated. 2009;13:263-268.

6. Anantha krishnan N. Objective structured clinical/practical examination (OSCE/OSPE). J Postgrad Med. 1993;39(2):82-84.

7. Hall-Turner WJ. An experimental assessment carried out in an undergraduate general practice teaching course (OSCE examination). Med Educ. 1983;17(2):112-119.

8. Walker R, Walker B. Use of the objective structured clinical examination for assessment of vocational trainees for general practice. $J R$ Coll Gen Pract. 1987;37(296):123-124.

9. Harden RM. Twelve Tips for Organizing Objective Structured Clinical Examinations. (OSCE) Medical Teacher. 1991;12(3-4):259-264. 